\title{
Upper stratospheric ozone decrease events due to a positive feedback between ozone and the ozone dissociation rate
}

\author{
G. R. Sonnemann ${ }^{1,2}$ and P. Hartogh ${ }^{2}$ \\ ${ }^{1}$ Leibniz-Institute of Atmospheric Physics at the University of Rostock, Schloss-Str. 6, 18225 \\ Ostseebad Kühlungsborn, Germany \\ ${ }^{2}$ Max-Planck-Institute for Solar System Research, Max-Planck-Str. 2, 37191 Katlenburg-Lindau, Germany
}

Received: 6 February 2009 - Revised: 15 May 2009 - Accepted: 28 May 2009 - Published: 19 June 2009

\begin{abstract}
Ozone measurements taken with a ground based microwave instrument at Lindau $\left(51.66^{\circ} \mathrm{N}, 10.13^{\circ} \mathrm{E}\right)$ over some years showed strong ozone decrease events within the stratopause region, particularly during the winter half-year. These events are characterized by a marked drop of the ozone mixing ratio from two to three ppmv to less than half a ppmv in extreme cases. Simultaneous water vapor measurements at the same place, also carried out by a microwave instrument, showed a strong increase of its mixing ratio and the temperature was also enhanced during these episodes. The theoretical analysis brought evidence that these events result from a positive feedback in the complex radiatively-chemical system between the ozone column density and the ozone dissociation rate.
\end{abstract}

\section{Introduction and ozone observations}

Ozone observations in the stratopause region/mesosphere in middle latitudes revealed that the variability of ozone with a timescale of few weeks increases toward the stratopause compared with the variability in the lower mesosphere (e.g. Mcpeters, 1980; Sonnemann et al., 2007). In the past the so-called ozone deficit problem in the stratopause region consisting in a systematic underestimation of ozone by the standard models was discussed (Clancy et al., 1987; Eluszkiewicz and Allen, 1993; Siskind et al., 1995; Summers et al., 1996, 1997; Dessler et al., 1998; among others). Summers et al. (1997) wrote: "The dominant portion of the ozone deficit problem in standard models is a consequence of over-

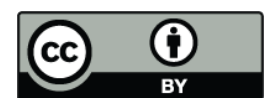

Correspondence to: G. R. Sonnemann (sonnemann@iap-kborn.de) estimation of the $\mathrm{OH}$ density in the upper stratosphere and lower mesosphere". In this context the question arises if the models consider all influences on the chemistry of this domain sufficiently correct. We will concentrate on the question how the ozone concentration in the stratopause region impacts its dissociation frequency and this feeds back to the ozone concentration due to a change of the chemical compostion by the altered dissociation rate.

Long-term observations of middle atmospheric ozone by means of microwave measurements at Lindau $\left(51.66^{\circ} \mathrm{N}\right.$, $\left.10.13^{\circ} \mathrm{E}\right)$ from April 1993 to October 1995 and since December 1998 brought evidence that strong ozone decrease events occur sporadically particularly during the fall and winter season. Figure 1 displays the mean nighttime ozone mixing ratios between 40 and $60 \mathrm{~km}$ for the period April 1993 to October 1995. The colored areas exhibit the running mean using a Gaussian function with a 7 day full width half maximum (FWHM), vertically displayed in $2.5 \mathrm{~km}$ steps. The primary measured data of the nighttime ozone mixing ratios are arithmetic means between sunset and sunrise. In order to emphasize the ozone decrease events we inserted contour lines into the figure calculated by a linear interpolation with a resolution of $1 \mathrm{ppmv}$. Very strong ozone decrease events occurred in October 1994 and in January 1995 with a decline of the values from 2-3 ppmv below half a ppmv. The October event particularly has the appearance of a deep local ozone hole. During further periods the drop of the ozone mixing ratios was not as strong but was still noticeable. There is high ozone variability just around the stratopause. The events last for a few weeks and the stage of ozone decrease takes place in one or two weeks. One recognizes an annual variation with maxima around summer solstice and minima during winter solstice in the upper stratosphere and lower mesosphere. Such ozone decrease events

Published by Copernicus Publications on behalf of the European Geosciences Union and the American Geophysical Union. 


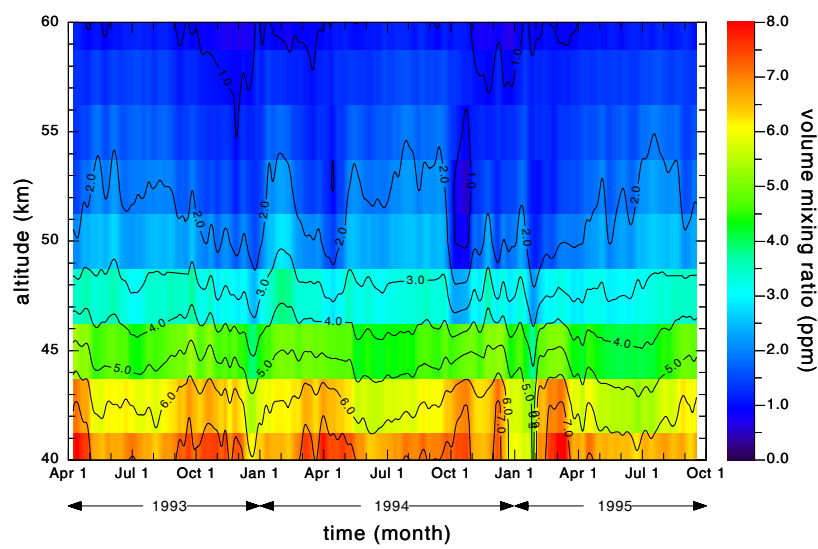

Fig. 1. Contour plot of nighttime ozone observed at Lindau $51.66^{\circ} \mathrm{N}$ from April 1993 to October 1995 showing some events of strong ozone decrease in the vicinity of the stratopause.

have also been observed (not shown) at the station ALOMAR $\left(69.29^{\circ} \mathrm{N}, 16.03^{\circ} \mathrm{E}\right)$ from October 1995 to June 1996, but they were not so marked.

For the ozone decrease event of October 1994 Fig. 2 illustrates this behavior depicting smoothed nighttime height profiles of the local ozone hole compared with the corresponding mean values of a period of 1 month before the hole occurred as a reference profile. The individual values of measurement drop partly below $0.5 \mathrm{ppmv}$ within the local ozone hole. At about $55 \mathrm{~km}$ the ozone concentration begins to decrease and reaches its strongest decline at about 50 to $52.5 \mathrm{~km}$. At about $45 \mathrm{~km}$ the effect begins to reverse and even shows an increase finally at $42.5 \mathrm{~km}$. Surprisingly, the nighttime values drop somewhat below the corresponding daytime values during the decreasing phase, whereas no significant diurnal variation has been found outside this. We also note that the absolute ozone values $\left(\mathrm{in}^{-3}\right.$ ) display a local minimum there.

As the characteristic chemical time of the odd oxygenodd hydrogen system (consisting of the main chemical active species $\left.\mathrm{O}_{3}, \mathrm{O}, \mathrm{O}\left({ }^{1} \mathrm{D}\right)-\mathrm{H}, \mathrm{OH}, \mathrm{HO}_{2}\right)$ amounts to about one day around the stratopause, the ozone decrease events cannot be explained by direct transport of air poor in ozone (the chief odd oxygen constituent there) from remote areas. However, parameters such as the temperature and the water vapor concentration can change their magnitude considerably with a time scale in the order of some days to few weeks. The average thermal behavior of the extended stratopause region in mean latitudes according to CIRA-86 is given by warm air in summer $\left(274 \mathrm{~K}, 50^{\circ}, 50 \mathrm{~km}\right.$, June) and cold air in winter $\left(253 \mathrm{~K}, 50^{\circ}, 50 \mathrm{~km}\right.$, December). The average temperature for September/October ranges around $260 \mathrm{~K}$. This general feature is interrupted in the winter season by the so-called sudden stratospheric warmings when the polar vortex breaks down and the air can be heated up to more than $300 \mathrm{~K}$.

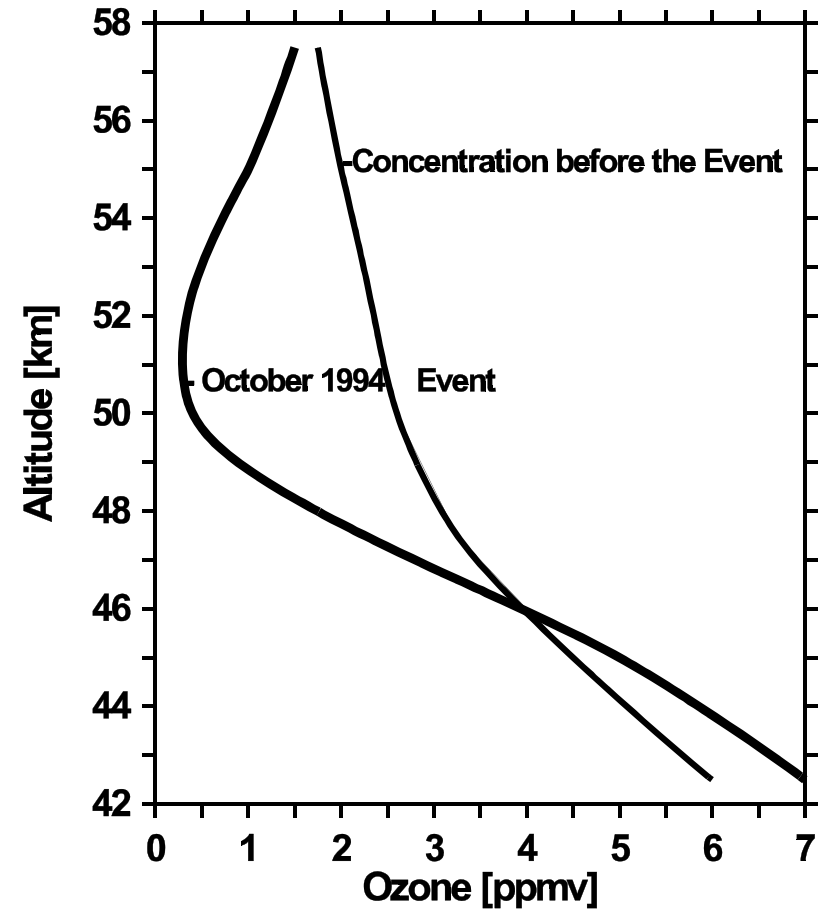

Fig. 2. The figure displays a vertical section through the local ozone hole of the October 1994 event compared with a smoothed profile of a 1 month mean before the episode began. Below about $46 \mathrm{~km}$ the effect reverses due to small water vapor mixing ratios there during the event.

The water vapor concentration possesses a marked annual variation in mean and high latitudes characterized by a concentration peak up to more than 7 ppmv just around the stratopause/lower mesosphere occurring from August to October (e.g. Seele and Hartogh, 1999; Körner and Sonnemann, 2001; Sonnemann and Grygalashvyly, 2005). Model calculations predict only a relatively slight dependence of the ozone concentration on temperature (according to the dependence of the reaction rates on temperature), water vapor or even on chlorine when it varies in natural borders (Frederick, 1980; Rusch et al., 1983; Solomon et al., 1983; Keating et al., 1985; Fichtelmann and Sonnemann, 1989).

\section{Water vapor observations and temperature measurements}

Fortunately, we have carried out simultaneous microwave water vapor measurements for the period of the decrease events considered. Figure 3 shows the results of observation. The most striking features are two events of strong enhancement of the water vapor mixing ratio exactly coinciding with the periods of the strong ozone decrease. As the chemistry of water vapor is too inert to produce (or also to destroy) such large water vapor concentrations, it should be transported 


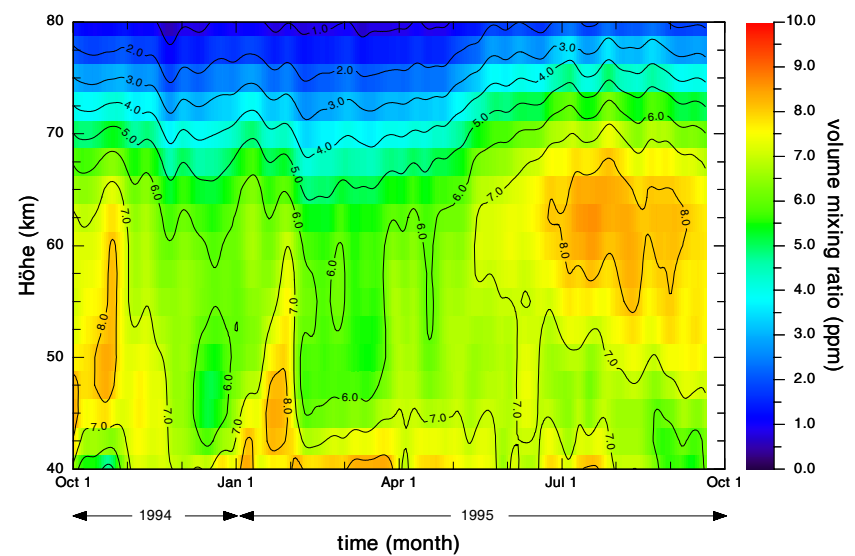

Fig. 3. Water vapor measurements at the same place of ozone observation showing very strong events of enhancements of the $\mathrm{H}_{2} \mathrm{O}$ mixing ratio simultaneously to the ozone decrease events.

from anywhere afar to the region of observation (see also discussion in Seele and Hartogh, 2000). The role of water vapor for the chemistry in the mesosphere/stratopause region was discussed in detail by Sonnemann et al. (2005). Water vapor is the main source gas for the chemically rather active hydrogen radicals which destroy catalytically odd oxygen. The effective chemical lifetime of water vapor at the stratopause, that is the lifetime which considers both the chemical loss and the chemical production (see Körner and Sonnemann, 2001 for definition), is extremely long and amounts to several months meaning water vapor is determined by transports in this domain. The hydrogen radicals formed by the photolysis of water vapor and their oxidation by $\mathrm{O}\left({ }^{1} \mathrm{D}\right)$ return to water vapor within so-called zero cycles (Sonnemann et al., 2005) producing only heat. Hence the place where these strange humid air bubbles came from and the source of the humidity are open questions. The feature looks like air welling up, but this statement is speculative. A possible cause taken into consideration is the exhaust of rockets. There were three launches of major rockets from Cape Canaveral in the weeks preceding each of the observed local ozone decrease events in mid-to-late October of 1994, in mid-January of 1995 and a third hint in early June 1995. These dates correspond to the launches of SST-68 on 30 September 1994 and Titan IV rocket on 22 December 1994 and 14 May, 1995. However, the measured water vapor bubbles last longer than a week and the vertical extension is in the order of $10 \mathrm{~km}$ or more beginning at $45 \mathrm{~km}$ for the October event. Even for a slow zonal wind speed of the middle atmospheric wind jet during this event the zonal extension of the bubble would amount thousands of kilometers. This is definitely too large for a rocket cloud of exhaust. It was found by means of balloon measurements a strong increase of the stratospheric water vapor in the past before 2000 (Oldmans and Hofmann, 1995; Evans et al., 1998) which could only be explained to $40 \%$ by the

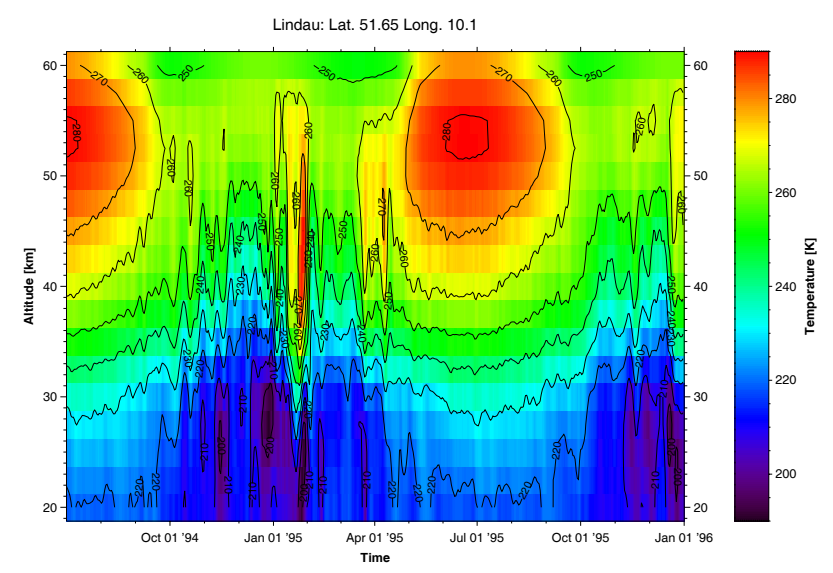

Fig. 4. Temperature measurements up to $52 \mathrm{~km}$ by the National Center for Environmental Prediction for a latitude corresponding to that of Lindau. Above that height the temperature has been gradually adopted to the MSIS-model. The measurements indicate a stratospheric warming during the January 1995 ozone decrease event and a moderate enhancement for the October 1994 episode.

methane increase (Foster and Shine, 1999) and thus it seems to be unexplained (Kley et al., 2000). Possibly, an enhanced water vapor content of the stratosphere results from singular events of water vapor injection from the troposphere.

Figure 4 exhibits the smoothed temperature between 20 and $60 \mathrm{~km}$ including the period considered according to measurements of the National Center for Environmental Prediction (McPherson et al., 2000) up to $52 \mathrm{~km}$. Above this height the measurements have been gradually adapted to the MSIS model data (Hedin, 1991). Evidently the ozone decrease events and water vapor enhancements are connected with a (slight) increase of the temperature, additionally chemically influencing the ozone decrease and possibly entailing a welling up of humid air, perhaps connected with a meridional transport of more humid air from the north. The temperature increase, according to these smoothed data, is not so marked during the October event but it seems to be connected with a stratospheric warming for the event in January 1995.

\section{Ozone dissociation frequency}

Ozone is the only chemically variable constituent of which dissociation frequency depends on its column density. (The ozone dissociation rate is the product of the ozone dissociation frequency with the concentration of ozone.) The dissociation frequency of molecular oxygen also depends on the $\mathrm{O}_{2}$-column density, but its dissociation frequency is too small to influence the $\mathrm{O}_{2}$-density noticeably. For all other constituents in the middle atmosphere it holds that the main absorption of solar radiation contributing to the dissociation frequencies of these constituents takes place by molecular oxygen and/or ozone determining the magnitude of their 


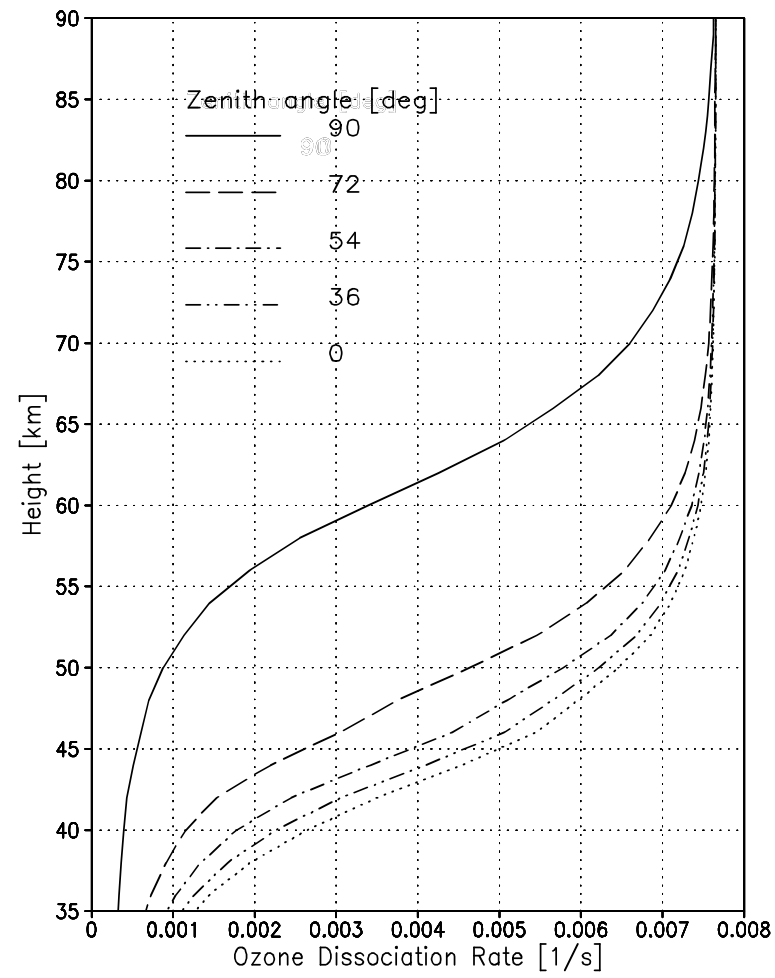

Fig. 5. Ozone dissociation frequency for 5 different solar zenith angles. The strongest decrease of the frequency with decreasing height for solar zenith angles greater than $54^{\circ}$ takes place around the stratopause.

dissociation frequencies. E.g. the dissociation frequency of water vapor at a certain height is chiefly determined by the absorption by $\mathrm{O}_{2}$. The absorption by water vapor itself plays no role. The dissociation of ozone results in the formation of atomic oxygen, mainly in the exited state $\mathrm{O}\left({ }^{1} \mathrm{D}\right) . \mathrm{O}\left({ }^{1} \mathrm{D}\right)$ is chemically a rather active species oxidizing $\mathrm{H}_{2} \mathrm{O}, \mathrm{H}_{2}$ and $\mathrm{CH}_{4}$ forming hydrogen radicals which destroy ozone catalytically. However, the greatest part of $\mathrm{O}\left({ }^{1} \mathrm{D}\right)$ atoms is subjected to quenching reactions by collisions with air molecules resulting in atomic oxygen in the ground state, and the largest part of atomic oxygen returns to ozone again by the important three-body reaction $\mathrm{O}+\mathrm{O}_{2}+\mathrm{M} \rightarrow \mathrm{O}_{3}+\mathrm{M}$ depending quadratically on the air density. But an increase of the flowing equilibrium of $\mathrm{O}$ and an amplified formation of hydrogen radicals destroy odd oxygen and influences the catalytic cycles in that they become more effective. On the one hand atomic oxygen reacts with ozone. On the other hand an effective catalytic cycle consists of the following three reactions:

$$
\begin{aligned}
& \mathrm{O}+\mathrm{OH} \rightarrow \mathrm{O}_{2}+\mathrm{H} \\
& \mathrm{H}+\mathrm{O}_{2}+\mathrm{M} \rightarrow \mathrm{HO}_{2}+\mathrm{M} \\
& \mathrm{HO}_{2}+\mathrm{O} \rightarrow \mathrm{OH}+\mathrm{O}_{2} \\
& \text { net }: \mathrm{O}+\mathrm{O} \rightarrow \mathrm{O}_{2}
\end{aligned}
$$

Figure 5 displays the ozone dissociation frequency for 5 different solar zenith angles $\chi$ including $54^{\circ}$, which is approximately the solar zenith angle at noon at Lindau during equinox. The dissociation frequencies are taken from Fichtelmann and Sonnemann (1989), Sonnemann et al. (1998) and Röth (1992). They combine a code developed for thermospheric-mesospheric as well as for stratospheric models and are used in the GCMs COMMA-IAP (COlogne Model of the Middle Atmosphere of the Institute of Atmospheric Physics, e.g. Sonnemann et al., 2005) and LIMA (Leibniz-Institute Middle Atmosphere model, e.g. Sonnemann et al., 2008). The dissociation frequency is almost constant within the whole mesosphere, with the exception of the lowermost domain. The absorption cross section of ozone has an order of $10^{-17} \mathrm{~cm}^{2}$, meaning the column density of ozone needs an order of $10^{17} \mathrm{~cm}^{-2}$ to produce an optical depth of unity. The column density at a certain altitude is given by the product of the density at this height with a mean density scale height along the penetration path of absorbed radiation multiplied by the Chapman-function $\mathrm{Ch} \chi(\approx \sec \chi$ for $\left.\chi \leq 75-80^{\circ}\right)$. The Chapman-function takes the increase of the column density along the penetration path of the incident radiation of a zenith angle $\chi$ into calculation. The density scale height along the penetration path of radiation is not constant; it depends on height and, less strongly, on $\chi$. The mean scale height is that equivalent value (depending on height and zenith angle) that the column densities calculated on the one hand with the mean scale height and on the other hand with the real variable density scale height is the same. A coarse value for the ozone density scale height is $5 \mathrm{~km}$. Hence, a noticeable decrease of the ozone dissociation frequency starts not much before the ozone density reaches an order of $10^{10} \mathrm{~cm}^{-3}$ (meaning the optical depth $\tau$ for overhead sun $\left(\chi=0^{\circ}\right)$ amounts to $\left.\tau=10^{10} \times 5 \times 10^{5} \times 10^{-17}=0.05\right)$ and this value corresponds to about $60 \mathrm{~km}$. The strongest decrease of the ozone dissociation frequency with decreasing height occurs around the stratopause. The altitude of the strongest decrease of the dissociation frequency rises with the increasing solar zenith angle. A change, say a decrease, of the ozone density due to an increase of the humidity or/and temperature within a certain height interval above the height under consideration entails an increase of the ozone dissociation frequency. But the increased ozone dissociation frequency strengthens further the ozone decomposition etc. by the reactions mentioned above. This effect amplifies with increasing distance from the upper border of this interval so that this is an example of a non-classical feedback for which an integral over a certain domain determines the response at the considered location. This kind of feedback could be termed a "feedback under global constraints" (Sonnemann, 1998). A negative feedback having to be discussed is connected with the so-called self-healing effect. Ozone also absorbs radiation dissociating molecular oxygen into atomic oxygen which is quickly converted into ozone damping the radiation. However, the dissociation for $\mathrm{O}_{2}$ begins at 
$242.4 \mathrm{~nm}$ in the Herzberg continuum with an extreme small cross section. The main photolysis of molecular oxygen in the domain under consideration takes place in the SchumannRunge bands with wavelength below $200 \mathrm{~nm}$. The main dissociation of ozone takes place in the Hartley bands around $250 \mathrm{~nm}$ and thus, the stronger radiation does not worth mentioning dissociate $\mathrm{O}_{2}$ but penetrates only somewhat deeper into the atmosphere. A further negative feedback which has to take into consideration results from the fact that on the one hand the dissociation frequency increases, but on the other hand with decreasing ozone concentration the dissociation rate (being the product of increasing dissociation frequency and decreasing ozone concentration which determines the production term of atomic oxygen) is damped.

\section{A simplified chemical model of the ozone dissociation rate-ozone column density feedback}

Usually, the description of details of the current global models in the publications is very limited and therefore, it is difficult to judge whether or not this feedback has been correctly considered. Normally, the models use ozone dissociation frequencies given as tables calculated for discrete steps of height or of pressure and of the solar zenith angle (possibly still depending on season and latitude). In order to investigate the behavior of the chemical system when considering this feedback, we developed a simple dynamical model. The height in the model under consideration was determined by the aeronomical conditions, such as the density of air and consequently of molecular oxygen, molecular hydrogen of $0.5 \mathrm{ppmv}$ and other constituents and the dissociation frequencies of water vapor and molecular oxygen etc. The water vapor mixing ratio, the temperature, the $\mathrm{ClO}_{\mathrm{x}}$-mixing ratio then act as control parameters. (A control parameter is a parameter fixed for each model run which is stepwise increased or decreased from one model run to the next one using the old final values as new initial values.)

All chemically active constituents, i.e. constituents of the odd oxygen $\left(\mathrm{O}, \mathrm{O}_{3}\right.$, and $\left.\mathrm{O}\left({ }^{1} \mathrm{D}\right)\right)$, the odd hydrogen $(\mathrm{H}, \mathrm{OH}$, $\mathrm{HO}_{2}$, and $\left.\mathrm{H}_{2} \mathrm{O}_{2}\right)$ and the odd nitrogen families $\left(\mathrm{N}\left({ }^{4} \mathrm{~S}\right)\right.$, $\mathrm{NO}$, $\mathrm{NO}_{2}, \mathrm{NO}_{3}$ ), are integrated separately meaning not as family. We integrate the stiff chemical system with a self-adjusting time step in the way that the largest absolute change of the concentration of any constituent does not exceed 1 per mil. This procedure was employed to calculate the bifurcation diagram of the non-linear response of the chemical system in the mesopause region which requires highest precision to determine the bifurcation points (e.g. Fichtelmann and Sonnemann, 1992; Sonnemann and Fichtelmann, 1997; Sonnemann and Feigin, 1999). The method of self-adjusting time step was also used by McKenna et al. (2002) to calculate the ozone chemistry within the polar vortex. The chemical code including the chemical reaction rates are taken from our 3-D models (e.g. Sonnemann et al., 1998, 2005, 2008;
Hartogh et al., 2004). The $\mathrm{ClO}_{\mathrm{x}}$-mixing ratio was taken as constant for each model run but the partitioning between the share of $\mathrm{Cl}$ and $\mathrm{ClO}$ was variable depending on the odd oxygen chemistry. The mesosphere and the stratopause region (above about $40 \mathrm{~km}$ ) can widely be described by a pure odd oxygen-odd hydrogen chemistry (Crutzen et al., 1995), but below that domain the catalytic ozone destruction by the chlorine species becomes increasingly important so that we also consider the ozone decomposition by these constituents. $\mathrm{NO}_{\mathrm{x}}$-species were considered but they play no role in that domain. In this context we also have checked that no solar proton event occurred during the time of the ozone decrease events observed. The sensitivity was studied with regard to the $\mathrm{O}_{2}$-dissociation frequency and the air density (pressure change). The most important question is how does the ozone dissociation frequency depend on the locally calculated ozone concentration? The answer requires assumptions about the ozone distribution above the height under consideration.

The ozone column density determines the ozone dissociation frequency. The ozone column density used for calculation of the dissociation frequency is given, as mentioned above, by

$N_{\mathrm{O}_{3}}(z, t, \chi)=n_{\mathrm{O}_{3}}(z, t) \overline{H_{\mathrm{O} 3}}(z, t) \mathrm{Ch}(\chi)$

depending on height $z$, time $t$ and the solar zenith angle $\chi(t)$. $n_{\mathrm{O}_{3}}(z, t)$ is the ozone density at $z, \overline{H_{\mathrm{O}_{3}}}(z, t)$ stands for the mean density scale height of ozone at $z$ along the path of penetration of radiation (it depends only little on $\chi$ ). For the mean scale height we used the expression

$\overline{{ }^{x} H_{\mathrm{O}_{3}}(\mathrm{z}, \mathrm{t})}=\overline{{ }^{0} H_{\mathrm{O}_{3}}(\mathrm{z}, 0)}\left(n_{\mathrm{O}_{3}}(z, 0) / n_{\mathrm{O}_{3}}(z, t)\right)^{(1-x)}$

The argument $t$ indicates the time depending ozone values calculated by the model and 0 stands for a constant model value determining the dissociation frequency in the conventional case without consideration of the feedback $\left(n_{\mathrm{O}_{3}}(50,0)=2.4 \mathrm{ppmv}\right)$. A value $x=1$ means that the mean density scale height of ozone ${ }^{1} \overline{\mathrm{H}_{\mathrm{O}_{3}}}(z, t)={ }^{0} \overline{\mathrm{H}_{\mathrm{O}_{3}}}(z, 0)$ does not depend on the time-depending $n_{\mathrm{O}_{3}}(\mathrm{z}, \mathrm{t})$ in the model (a strong feedback case). In this case, the ozone dissociation frequency at a constant altitude depends directly on the local ozone density, meaning the mean scale height stays constant at a value given before the calculation. Values between 1 and 0 increasingly soften the positive feedback and values greater than unity would strengthen it. Values less than zero are possible if an ozone bulge occurs.

\section{Model calculations by means of a simplified model}

We have performed a large number of computer experiments with approximated ozone dissociation frequencies. The idealized model assumptions were intended to demonstrate the positive feedback between ozone and the ozone dissociation rates resulting in the development of a local ozone hole under 


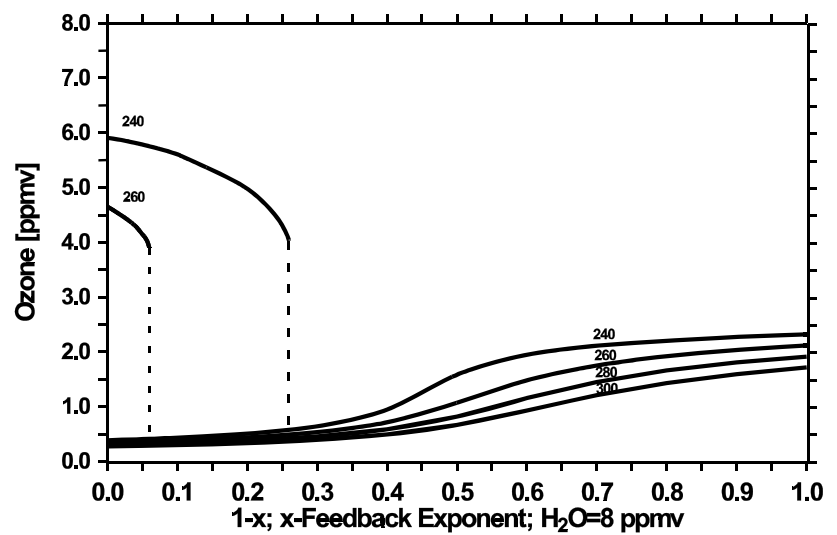

Fig. 6a. Nighttime ozone mixing ratios at $50 \mathrm{~km}$ for equinox conditions and a water vapor mixing ratio of 8 ppmv depending on the feedback parameter $x$. The parameter is the temperature. The system creates a trigger solution only for high feedback parameters and lower temperatures, but generally the ozone values decreases with increasing feedback parameters having values as low as below 0.5 ppmv already for moderate feedback parameters and higher temperatures.

special aeronomical conditions. The calculations help to understand the phenomenon observed. A real calculation of this phenomenon is only possible in the frame of a completely interactively operating 3-D-model which computes the ozone dissociation frequency of each time step on the basis of the current ozone distribution within the whole height range; but according to our knowledge such a model is not yet available. We show results here according to the latitude of Lindau at 50 and $45 \mathrm{~km}$ altitude for equinox (half a day sunshine).

The feedback is restrained to a certain extent by an increase of the mean scale height determining the ozone column density without, of course, compensating for the effect completely. The only relevant magnitude determining the ozone dissociation frequency is the ozone column density. Fig. 6a displays calculations of an example for a water vapor mixing ratio of 8 ppmv according to the observation in the period of strongest ozone decrease. Although the differences between daytime and nighttime values are small, we show generally nighttime values. The control parameter is, according to Eq. (2), the exponent 1-x considering the power of feedback. The parameter for the individual curves is the temperature. A trigger solution exists for smaller temperatures but only under the assumption of strong feedback (small values of 1-x). Apart from that, the curves decrease monotonically with increasing feedback, however, the gradient becomes steeper with dropping off temperatures within a certain interval of the control parameter. It is an important result that, particularly for higher temperatures, the ozone mixing ratios fall below 0.5 ppmv even for weaker feedbacks and that the upper solution cannot be taken on for $\mathrm{x}$-values less than unity. The simple reason for this latter assertion re-

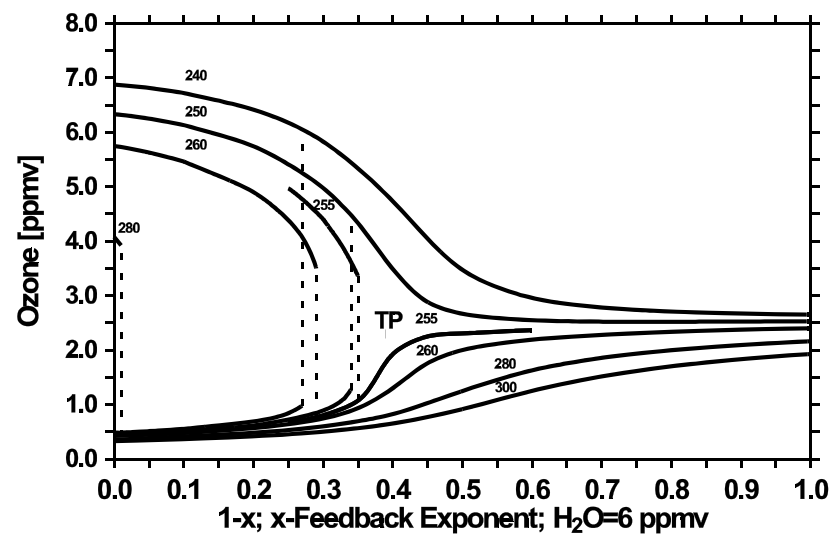

Fig. 6b. The same state of affairs as depicted in Fig. 6a but for 6 ppmv $\mathrm{H}_{2} \mathrm{O}$ mixing ratio. The diagram is more complicated now. The feedback results in increasing ozone mixing ratios for lower temperatures (the critical temperature is about $254.1 \mathrm{~K}$ ) whereas for higher temperature the values decrease. A trigger solution exists for $\mathrm{x}$-values greater than 0.61 .

sults from the fact that, under natural conditions, the system starts from a catchment region which belongs to the lower solution.

Figure $6 \mathrm{~b}$ shows the same state of affairs as displayed in Fig. 6a but for a water vapor mixing ratio of $6 \mathrm{ppmv}$. This value corresponds more to mean conditions. Also in this case the upper trigger solution occurs only for a stronger feedback. There is a triple point for $254.1 \mathrm{~K}$ at about $1-x=0.39$ and a ozone mixing ratio of $2.48 \mathrm{ppmv}$. For temperatures greater than this value, the ozone concentration decreases monotonically with decreasing feedback parameter $1-x$ but a trigger solution exists for values less than a certain critical value $(1-x)_{c}$ which depends on temperature. The larger the temperature the smaller $(1-x)_{c}$ is. For temperatures less than $254.1 \mathrm{~K}$ the ozone concentration increases monotonically with decreasing feedback parameters and a trigger solution also occurs for feedback parameter values less than the temperature depending on values $(1-x)_{c}$. Obviously, a strong ozone enhancement at $50 \mathrm{~km}$ has not been observed thus far. It would require that the ozone column density is very high, meaning the ozone density has to be high over a sufficiently extended height interval above the altitude considered. This possibility is, however, reduced by the fact that with increasing height the ozone amplification effect becomes more inefficient so that the feedback parameter does not have sufficiently large values.

Figure $6 c$ depicts calculations according to a height of $45 \mathrm{~km}$. The control parameter is the water vapor mixing ratio and the parameter of the individual curves is the feedback parameter 1- $x$. The temperature amounts to $260 \mathrm{~K}, n_{\mathrm{O}_{3}}(0)$ corresponds to $4.5 \mathrm{ppmv}$ now, it is $\mathrm{ClO}_{\mathrm{x}}=0.4 \mathrm{ppbv}$. Additionally, we have included the curve for $T=250 \mathrm{~K}$ and $x=1$. It ranges nearly $1 \mathrm{ppmv}$ higher than the corresponding one 
for $T=260 \mathrm{~K}$. There is a trigger solution for large feedback parameter values only. The critical $\mathrm{H}_{2} \mathrm{O}$ mixing ratio for a state transition is shifted to greater values for smaller temperatures. Considering the episode from October 1994 the system stayed in the upper solution due to the relatively low $\mathrm{H}_{2} \mathrm{O}$ mixing ratios and moderate temperature at $45 \mathrm{~km}$. This is, at least, the common case at that height. Instead, the ozoneozone dissociation rate feedback may normally increase the ozone mixing ratio at this and lower altitudes compared with results not considering the feedback.

\section{Discussion}

Multiple publications have dealt with the so-called ozone deficit problem consisting in a systematic underestimation of ozone by the standard models (e.g. Clancy et al., 1987; Eluszkiewicz and Allen, 1993; Siskind et al., 1995; Summers et al., 1996, 1997; Dessler et al., 1998). A more detailed description of the employed models is usually not given. Thus, perhaps there is a systematic underestimation of the ozoneozone dissociation rate feedback by the models in the domain of the upper stratosphere. However, in contrast to this assertion (Crutzen et al., 1995) did not find evidence for an ozone deficit.

We have estimated the feedback parameter $x$ depending on height for the October 1994 episode according to the smoothed values shown in Fig. 2. The parameter $x$ has been calculated on the basis of expression (2). The mean density scale height is generally defined by

$\bar{H}(z)=\int_{z}^{\infty} \exp \left(-\frac{z^{\prime}-z}{H\left(z^{\prime}\right)}\right) d z^{\prime}$.

The density scale height $H\left(z^{\prime}\right)$ can be derived approximately from the measured density values. Both the curves of Fig. 2 yield a different mean scale height. ${ }^{x} \bar{H}$ results from the curve of the observed local ozone hole values and ${ }^{0} \bar{H}$ from the curve representing the densities before the event arose. Coming from high altitudes, the parameter 1- $x$ used in Fig. 6a, b as a control parameter slowly begins to increase. At $50 \mathrm{~km}$ the value amounts to about 0.64 and at $49 \mathrm{~km}$ to about 0.38 . The zero line is crossed between 48 and $49 \mathrm{~km}$. A pole occurs between 45 and $46 \mathrm{~km}$ where $x$ becomes infinity and changes its sign for lower heights. For further decreasing heights the negative values seems to approach zero again. The pole is determined when the hole becomes a bulge below 45 to $46 \mathrm{~km}$. Approximately at this height the mean density scale height has its smallest value with $2.7 \mathrm{~km}$ whereas the value for the reference case is about $4.7 \mathrm{~km}$. We have to keep in mind that the measured ozone values are averaged over $7-10 \mathrm{~km}$ and smoothed after that and the reference values are only an approximated estimate. In particular, those ozone mixing ratios observed around the minimum cannot be determined accurately. The temperature is not precisely known and is

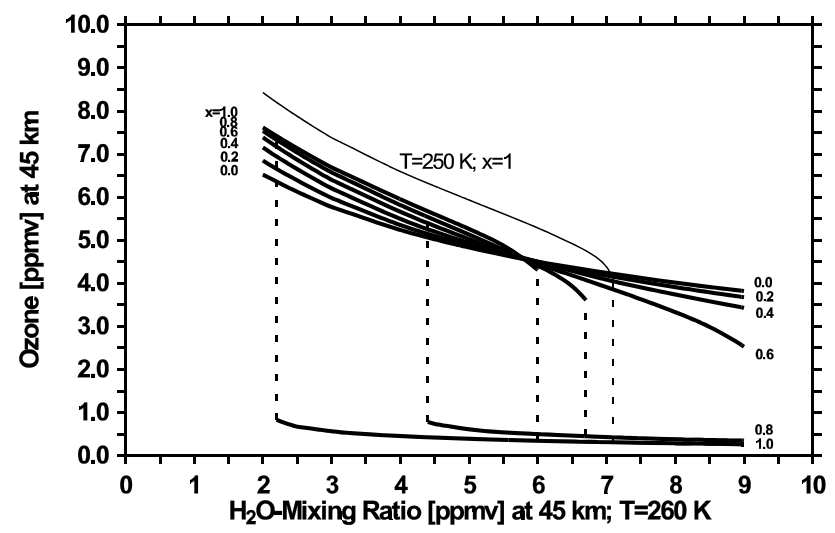

Fig. 6c. Nighttime ozone mixing ratios for equinox conditions and $T=260 \mathrm{~K}$ at $45 \mathrm{~km}$ depending on the water vapor mixing ratio. The parameter is the feedback parameter. Additionally the figure shows the curve for $T=250 \mathrm{~K}$ and $x=1$. The system produces the lower ozone solution only for very strong feedback parameters values and high $\mathrm{H}_{2} \mathrm{O}$ mixing ratios.

probably underestimated. Despite these restrictions, the $\mathrm{x}$ value around $49 \mathrm{~km}$ corresponding to the lower state agrees surprisingly well with the results shown in Fig. 6 a for $50 \mathrm{~km}$. Evidently, at $45 \mathrm{~km}$ and below there is only one solution for a water vapor concentration of $8 \mathrm{ppmv}$ and negative $\mathrm{x}$-values corresponding to the upper state. Normally the water vapor mixing ratio is not so large and consequently the system response is not so strong. Depending on the temperature, the ozone values can slightly decrease or increase compared with the case of $x=0$ as Fig. $6 \mathrm{~b}$ illustrates.

In context with the decline of the ozone layer due to the anthropogenic impact by $\mathrm{ClO}_{\mathrm{x}}$ and $\mathrm{NO}_{\mathrm{x}}$ the first sign of a reduction of the ozone concentration was found by means of Umkehr measurements in the upper stratosphere (Reinsel et al., 1984, 1987). Also the strongest response was expected in that domain. However, the impact of these species on ozone is very limited at the stratopause and the stronger influence results from a change of the water vapor concentration and the temperature. Due to the rising methane concentration resulting from anthropogenic methane release from different sources (Rasmussen and Khalil, 1984; Khalil et al., 1993; Kheshgi et al., 1999) and its oxidation to water vapor in the middle atmosphere, and as a result of an additional increase of the humidity in the stratosphere (Thomas et al., 1989; Thomas and Olivero, 2001), the number of ozone decrease events should rise, at least, the response becomes stronger. Consequently, the trend of the ozone decline around the stratopause region should mainly result from the increasing humidity of the middle atmosphere. However, in the recent past this trend seems to have stopped or slowed down considerably (Dlugokencky et al., 2003). Only one part of the stratospheric variation of water vapor can be contributed to the methane oxidation. The other part results from 
a natural variability such as the Brewer-Dobson circulation connected with exchange processes between troposphere and stratosphere (Foster and Shine, 1999). The global circulation also influences the water vapor transport in the mesosphere of high latitudes. On the other hand, a cooling of the middle atmosphere by the increasing $\mathrm{CO}_{2}$-concentration should soften this effect. Possibly, the negative feedback by the reduced ozone concentration as the main absorber of UV-radiation being the chief energy input into the middle atmosphere is more important. This effect cannot, of course, compensate for the ozone reduction but it can only reduce the decline to a certain extent.

\section{Trigger solutions in chemical systems of the atmo- sphere and conclusions}

The possibility of trigger solutions of the chemical systems within the atmosphere was first introduced by Prather et al. (1979) and Fox et al. (1982) for a simplified system of the stratospheric odd nitrogen chemistry. Later on various researchers (White and Dietz, 1984; Kasting and Ackermann, 1985; Kleinman, 1991; Zimmermann and Poppe, 1993; Stewart, 1993; Poppe and Lustfeld, 1996; and other groups) discussed a low and high ozone regime in the chemistry of the boundary layer. Under consideration of vertical transport Yang and Brasseur (1994) found a trigger solution in the chemistry of the mesosphere and finally Feigin and Konovalov (1996) discovered a multiple solution in the highlatitude stratospheric photochemical system.

The investigations by means of an idealized model do not fit the reality in any case. Hence, it is not clear whether the natural system operates in a bistable mode under particular conditions or not. In the positive case we expect that only the lower ozone solution can occur in the range of positive $\mathrm{x}$ values, whereas in the lower domain for negative $\mathrm{x}$-values the upper solution may prevail. The transition regions from the lower to an upper solution have not been considered. The occurrence of a lower solution requires very high water vapor mixing ratios and high temperatures (such as occur during stratospheric warmings) within a sufficiently extended height range around the stratopause. Definitely, as Fig. 6a demonstrated, the ozone mixing ratio drops below 1 ppmv for relatively weak feedback parameters and even below $0.5 \mathrm{ppmv}$ for stronger ones. Such strong events have been observed.

The search for similar events in the data of the latest years until 2008 revealed different episodes of ozone decrease, but, in contrast to the expected behavior, they were not so marked as those in the early nineteenth. During the episodes after 1999 the ozone mixing ratios declined from more than 2 ppmv to minimum 1 ppmv, sometimes connected with stratospheric warmings, but decrease events also occurred in summer. There are also events of sudden ozone enhancements in winter characterized by values larger than 3.5 ppmv. Unfortunately, there were no simultaneous wa- ter vapor measurements at Lindau. However, measurements in ALOMAR showed a general decrease of the water vapor concentration since 2000 after a phase of considerable increase. As reported by Randel et al. (2006) and Scherer et al. (2008) the Brewer-Dobson circulation in the tropics changed abruptly after 2001 impacting the water vapor distribution in the lower stratosphere. Bittner et al. (2000) and Höppner and Bittner (2007) found a slowdown of the planetary wave activity also in middle latitudes. Particularly the values during the winter season became noticeable smaller what could explain that the latest events were less pronounced. Thus the enhancement episodes could be linked with episodes of strong water vapor decrease. Pronounced ozone decrease episodes are very few events occurring under exceptionally favorable conditions of very large water vapor concentrations in the order of $8 \mathrm{ppmv}$ and additionally high atmospheric temperatures. In this case real state transitions seems to be possible whereas normally only an amplified ozone change takes place indicated by the high short-term variability of ozone around the stratopause resulting from the ozone-ozone dissociation rate feedback.

It is very interesting to note that in the Martian atmosphere the ozone dissociation frequency also depends on the ozone concentration itself. The main Martian constituent $\mathrm{CO}_{2}$ has only a very small absorption cross section in the Hartley bands. A discrepancy between ozone measurements and model calculations (Lefèvre et al., 2004) between 30 and $60 \mathrm{~km}$ altitude was stated in Lebonnois et al. (2006). This is just the height range in which the ozone dissociation frequency strongly decreases with decreasing height.

Acknowledgements. This work was supported by the German Research Community DFG, grant So 268/4-1.

We greatly appreciate the assistance of Christopher Jarchow and Michailo Grygalashvyly in preparing some plots.

The service charges for this open access publication have been covered by the Max Planck Society.

Edited by: U. Feudel

Reviewed by: two anonymous referees

\section{References}

Bittner, M., Offermann, D., and Graef, D.: Mesopause temperature variability above midlatitudev station in Europe, J. Geophys. Res., 105, 2045-2058, 2000.

CIRA-86: Part II Middle Atmosphere Models, edited by: Rees, D., Barnett, J. J., Labitzke, K. Clancy, R. T., and Rusch, D. W., Solar Mesosphere Explorer Temperature Climatology of the mesosphere as compared to CIRA Model, Adv. Space Res., 10(12), 187-206, 1986.

Clancy, R. T., Rusch, D. W., Thomas, R. J., Allen, M., and Eckman, R. S.: Model ozone photochemistry on the basis of solar mesospheric explorer mesospheric observations, J. Geophys. Res., 92, 3067-3080, 1987. 
Crutzen, P. J., Grooß, J.-U., Brühl, C., Müller, R., and Russel III, J. M.: A reevaluation of the ozone budget with HALOE UARS data: No evidence of the ozone deficit, Science, 268, 705-708, 1995.

Dessler, A. E., Burrage, M. D., Grooss, J.-U., et al.: Selected science highlights from the first 5 years of the Upper Atmospheric Research Satellite (UARS) program, Rev. Geophys., 36, 183210, 1998.

Dlugokencky, E. J., Houweling, S., Bruhwiler, L., Masarie, K. A., Lang, P. M., Miller, J. B., and Tans, P. P.: Atmospheric methane levels off: Temporary pause or a new steady-state?, Geophys. Res. Lett., 30, 1992, doi:10.1029/2003GL018126, 2003.

Eluszkiewicz, J. and Allen, M.: A global analysis of the ozone deficit in the upper stratosphere and lower mesosphere, J. Geophys. Res., 98, 1069-1082, 1993.

Evans, S. J., Toumi, R., Harries, J. E., Chipperfield, M. P., and Russel, J. M.: Trends in stratospheric humidity and the sensitivity of ozone to these trends, J. Geophys. Res., 103, 8715-8725, 1998.

Feigin, A. M. and Konovalov, I. B.: On the possibility of the complicated dynamic behavior of atmospheric photochemical system: Instability of the Antarctic photochemistry during ozone hole formation, J. Geophys. Res., 101, 26023-26038, 1996.

Fichtelmann, B. and Sonnemann, G.: On the variation of ozone in the upper mesosphere and lower thermosphere: A comparison between theory and observation, Z. Meteorol., 39, 297-308, 1989.

Fichtelmann, B. and Sonnemann, G.: Non-linear behaviour of the photochemistry of minor constituents in the mesosphere, Ann. Geophys., 10, 719-728, 1992.

Foster, P. M. de F. and Shine, K. P.: Stratospheric water vapour changes as a possible contributor to observed stratospheric cooling, Geophys. Res. Lett., 26, 3309-3312, 1999.

Fox, J. L., Wofsy, S. C., McElroy, M. B., and Prather, M. J.: A stratospheric chemical instability, J. Geophys. Res., 87, 1112611132, 1982.

Frederick, J. E.: Seasonal variations in high-latitude ozone and metastable molecular oxygen emissions: A theoretical interpretation, J. Geophys. Res., 85, 1611-1617, 1980.

Hedin, A.: Extension of the MSIS thermosphere model into the middle and lower atmosphere, J. Geophys. Res., 96, 1159-1167, 1991.

Kasting, J. F. and Ackerman, T. P.: High atmospheric $\mathrm{NO}_{\mathrm{x}}$ levels and multiple photochemical steady states, J. Atmos. Chem., 3, 321-340, 1985.

Hartogh, P., Jarchow, C., Sonnemann, G. R., and Grygalashvyly, M.: On the spatiotemporal behavior of ozone within the mesosphere/mesopause region under nearly polar night conditions, J. Geophys. Res., 109, D18303, doi:10.1029/2004JD004576, 2004.

Keating, G. M., Brasseur, G. P., Nicholson III, J. Y., and de Rudder, A.: Detection of the response of ozone in the middle atmosphere to short-term solar ultraviolet variations, Geophys. Res. Lett., 12, 449-452, 1985.

Khalil, M. A. K., Rasmussen, R. A., and Moraes, F.: Atmospheric methane at Cap Meares: Analysis of a high-resolution data base and its environmental implications, J. Geophys. Res., 98, 1475314770, 1993.

Kheshgi, H. S., Jain, A. K., Kotamarthi, V. R., and Wuebbles, D. J.: Future atmospheric methane concentrations in the context of stabilization of greenhouse gas concentrations, J. Geophys. Res.,
104, 19183-19190, 1999.

Kleinman, L. I.: The low and high $\mathrm{NO}_{\mathrm{x}}$ regime, J. Geophys. Res., 96, 20721-20733, 1991.

Kley, D. J., Russell III, M., and Phillips, C. (Eds.): SPARC Assessment of Upper Tropospheric and Stratospheric Water Vapor, SPARC Tech. Rep., 2, 312 pp., 2000.

Körner, U. and Sonnemann, G. R.: Global 3D-modeling of water vapor concentration of the mesosphere/mesopause region and implications with respect to the NLC region, J. Geophys. Res., 106, 9639-9651, 2001.

Lebonnois, S., Quémerais, E., Montmessin, F., Lefèvre, F., Perrier, S., Bertaux, J.-L., and Forget, F.: Vertical distribution of ozone on Mars as measured by SPICAM/Mars Express using stellar occultations, J. Geophys. Res., 111, E09S05, doi:10.1029/2005JE002643, 2006.

Lefèvre, F., Lebonnois, S., Montmessin, F., and Forget, F.: Threedimensional modeling of ozone on Mars, J. Geophys. Res., 109, E07004, doi:10.1029/2004JE002268, 2004.

McKenna, D. S., Groß, J.-U., Günther, G., Konopka, P., Müller, R., Carver, G., and Sasano, Y.: A new chemical Lagrangian model of the stratosphere (CLaMS) 2. Formulation of chemistry scheme and initialization, J. Geophys. Res., 107(D15), 4256, doi:10.1029/2000JD000113, 2002.

Mcpeters, R. D.: The Behavior of Ozone Near the Stratopause From Two Years of BUV Observations, J. Geophys. Res., 85(C8), 4545-4550, 1980.

McPherson, R. S., Bergman, K. H., Kistler, R. E., Rasch, G. E., and Gordon, D. S.: The NMC Operational Global Data Assimilation System, Mon. Weather Rev., 107, 1445-1461, 1979.

Oldmans, S. J. and Hofmann, D. J.: Increase in lower stratospheric water vapour and a midlatitude northern hemisphere site from 1981-1994, Nature, 374, 146-149, 1995.

Poppe, D. and Lustfeld, H.: Nonlinearities in the gas phase chemistry of the troposphere: Oscillating concentrations in a simplified mechanism, J. Geophys. Res., 101, 14373-14380, 1996.

Prather, M. J., McElroy, M. B., Wofsy, S. C., and Logan, J. A.: Stratospheric chemistry: Multiple solutions, Geophys. Res. Lett., 6, 163-164, 1979.

Randel, W. J., Wu, F., Vömel, H., Nedoluha, G. E., and Forster, P.: Decreases in stratospheric water vapor after 2001: Links to changes in the tropical tropopause and the Brewer-Dobson circulation, J. Geophys. Res., 111, D12312, doi:10.1029/2005JD006744, 2006.

Rasmussen, R. A. and Khalil, M. A. K.: Atmospheric methane in the recent and ancient atmospheres: Concentrations, trends, and interhemispheric gradients, J. Geophys. Res., 89, 11599-11605, 1984.

Reinsel, G. C., Tiao, G. C., DeLuisi, J. J., Mateer, C. L., Miller, A. J., and Frederick, J. E.: Analysis of upper stratospheric Umkehr ozone profile data for trends and the effects of stratospheric aerosols, J. Geophys. Res., 89, 4833-4840, 1984.

Reinsel, G. C., Tiao, G. C., Miller, A. J., Wuebbles, D. J., Connell, P. S., Mateer, C. L., and DeLuisi, J. J.: Statistical analysis of total ozone and stratospheric Umkehr data for trends and solar cycle relationship, J. Geophys. Res., 92, 2201-2209, 1987.

Röth, E.-P.: Fast algorithm to calculate the photon flux in optically dense media for use in photochemical models, Ber. BunsenGesellsch, Phys. Chem., 96, 417-420, 1994.

Rusch, D. W., Mount, G. H., Barth, C. A., Rottman, G. J., Thomas, 
R. J., Thomas, G. E., Sanders, R. W., Lawrence, G. N., and Eckman, R. S.: Ozone density in the lower mesosphere measured by a limb scanning ultraviolet spectrometer, Geophys. Res. Lett., 10, 241-244, 1983.

Scherer, M., Vömel, H., Fueglistaler, S., Oltmans, S. J., and Staehelin, J.: Trends and variability of midlatitude stratospheric water vapour deduced from the re-evaluated Boulder balloon series and HALOE, Atmos. Chem. Phys., 8, 1391-1402, 2008, http://www.atmos-chem-phys.net/8/1391/2008/.

Seele, C. P. and Hartogh, P.: Water vapor of the polar middle atmosphere: Annual variation and summer mesosphere conditions as observed by ground-based microwave spectroscopy, Geophys. Res. Lett., 26, 1517-1720, 1999.

Seele, C. P. and Hartogh, P.: A case study on middle atmospheric water vapor transport during the February 1998 stratospheric warming, Geophys. Res. Lett., 27, 3309-3312, 2000.

Siskind, D. E., Connor, B. J., Eckman, R. S., Remsberg, E. E., Tsou, J. J., and Parrish, A.: An intercomparison of model ozone deficits in the upper stratosphere and mesosphere from two data sets, J. Geophys. Res., 100, 11191-11201, 1995.

Solomon, S., Rusch, D. W., Thomas, R. J., and Eckman, R. S.: Comparison of mesospheric ozone abundances measured by the Solar Mesospheric Explorer and model calculations, Geophys. Res. Lett., 10, 249-252, 1983.

Sonnemann, G.: On the formation of particlelike pattern, the amplitude modulated route to chaos and the wave-particle dualism in three-dimensional systems under global constraints, Prog. Theor. Phys., 99(6), 931-962, 1998.

Sonnemann, G. and Fichtelmann, B.: Subharmonics, cascades of period doubling, and chaotic behavior of photochemistry of the mesopause region, J. Geophys. Res., 102, 1193-1203, 1997.

Sonnemann, G., Kremp, Ch., Ebel, A., and Berger, U.: A threedimensional dynamic model of minor constituents of the mesosphere, Atmos. Environm., 32, 3157-3172, 1998.

Sonnemann, G. R. and Feigin, A. M.: Nonlinear behavior of a reaction-diffusion system of the photochemistry within the mesopause region, Phys. Rev. E, 59, 1719-1726, 1999.

Sonnemann, G. R. and Grygalashvyly, M.: Solar influence on mesospheric water vapor with impact on NLCs, J. Atmos. Sol.-Terr. Phy., 67, 177-190, 2005.
Sonnemann, G. R., Grygalashvyly, M., and Berger, U.: Autocatalytic water vapor production as a source of large mixing ratios within the middle to upper mesosphere, J. Geophys. Res., 110, D15303, doi:10.1029/2004JD005593, 2005.

Sonnemann, G. R., Hartogh, P., Jarchow, C., Grygalashvyly, M., and Berger, U.: On the winter anomaly of the night-to-day ratio of ozone in the middle to upper mesosphere in middle to high latitudes, Adv. Space Res., 40, 846-854, 2007.

Sonnemann, G. R., Hartogh, P., Grygalashvyly, M., Li, S., and Berger, U.: The quasi 5-day signal in the mesospheric water vapor concentration in high latitudes in 2003 - a comparison between observations at ALOMAR and calculations, J. Geophys. Res., 113, D04101, doi:10.1029/2007JD008875, 2008.

Stewart, R. W.: Multiple steady states in atmospheric chemistry, J. Geophys. Res., 98, 20601-20611, 1993.

Stewart, R. W.: Dynamics of the low to high $\mathrm{NO}_{\mathrm{x}}$ transition in a simplified tropospheric photochemical model, J. Geophys. Res., 100, 8929-8943, 1995.

Summers, M. E., Conway, R. R., Siskind, D. E., Bevilacqua, R., Strobel, D. F., and Zasadil, S.: Mesospheric $\mathrm{HO}_{\mathrm{x}}$ photochemistry: Constraints from recent satellite measurements of $\mathrm{OH}$ and $\mathrm{H}_{2} \mathrm{O}$, Geophys. Res. Lett., 23, 2097-2100, 1996.

Summers, M. E., Conway, R. R., Siskind, D. E., Stevens, M. H., Offermann, D., Riese, M., Preusse, P., Strobel, D. F., and Russel III, J. M.: Implications of satellite $\mathrm{OH}$ observations for middle atmospheric $\mathrm{H}_{2} \mathrm{O}$ and ozone, Science, 277, 1967-1970, 1997.

Thomas, G. E., Olivero, J. J., Jensen, E. J., Schröder, W., and Toon, O. B.: Relation between increasing methane and the presence of ice clouds at the mesopause, Nature, 338, 490-492, 1989.

Thomas, G. E. and Olivero, J. J.: Noctilucent clouds as possible indicators of global change in the mesosphere, Adv. Space Res., 28(7), 937-946, 2001.

White, W. H. and Dietz, D.: Does the photochemistry of the troposphere admit more than one steady state?, Nature, 309, 242-244, 1984.

Yang, P. and Brasseur, G.: Dynamics of the oxygen-hydrogen system in the mesosphere, 1. Photochemical equilibria and catastrophe, J. Geophys. Res., 99, 20955-20965, 1994.

Zimmermann, J. and Poppe, D.: Nonlinear chemical couplings in the tropospheric $\mathrm{NO}_{\mathrm{x}}-\mathrm{HO}_{\mathrm{x}}$ gas phase chemistry, J. Atmos. Chem., 17, 141-155, 1993. 